\title{
REFORMAR A ESCOLA PARA REFORMAR A VIDA: WALTER BENJAMIN, FORMAÇÃO E JUVENTUDE
}

Márcio Jarek ${ }^{1}$

Resumo: O artigo apresenta alguns aspectos da juventude do pensador Walter Benjamin (1892-1940). Esse período foi marcado pela recepção de uma proposta pedagógica que visava "reformar a vida" reformando, para isto, a escola e a cultura juvenil. Benjamin foi influenciado por essa proposta ao estudar em um colégio reformista em Haubinda e teve a figura do pedagogo progressista Gustav Wyneken (1875-1964), diretor da instituição, como sua primeira referência. Desse período restaram marcas que acompanharam a obra do filósofo, sobretudo aquelas que relativas à peculiaridade de sua crítica da cultura e pautadas nas noções de vida, de experiência e de formação.

Palavras-chave: Walter Benjamin, Reforma, Vida, Juventude, Formação

Reform the school for reform the life: walter benjamin, formation and youth

\begin{abstract}
The article presents some aspects of the youth of the thinker Walter Benjamin (1892-1940). This period was marked by the reception of a pedagogical proposal that aimed to "reform the life" by reforming, for this, the school and the youth culture. Benjamin was influenced by this proposal when studying in a reformist college in Haubinda and had the figure of the progressive pedagogue Gustav Wyneken (1875-1964), director of the institution, as his first reference. That period remaining marks that accompanied the philosopher's work, especially those relating to the peculiarity of his critique of culture and guided in life notions, experience and formation.
\end{abstract}

Keywords: Walter Benjamin, Reform, Life, Youth, Formation

${ }^{1}$ Doutor em filosofia pela PUC-Rio, professor da Universidade Tecnológica Federal do Paraná - UTFPR. E-mail: m.jarek@hotmail.com. 


\section{Introdução}

$\mathrm{Na}$ ocasião da juventude de Walter Benjamin (1907-1915) pode-se notar com intensidade o brilho de discussões, um tanto quanto exóticas para o todo da obra do autor, em relação ao assunto vida. Nesse momento de atividades intensas de formação escolar, logo seguido de sua formação universitária e acompanhado de perto pelo seu engajamento no movimento estudantil, parece brotar em Benjamin uma preocupação constante com a dinâmica da vida e suas representações. Muitas vezes, essa preocupação inicial surge permeada pelos dilemas existenciais "naturais" da idade, como aqueles que envolvem a descoberta da sexualidade, a escolha profissional ou a relação com os pais, mas em muitas ocasiões colocam o autor num campo de interação com os principais debates das escolas da chamada filosofia da vida (Lebensphilosophie).

De sua formação escolar ficaram os traços de uma proposta pedagógica inovadora que se propunha, a partir da reforma da escola e da juventude, reformar toda a vida. De seu engajamento no movimento estudantil e de seu contato, na época, com o judaísmo, restaram elementos "revolucionários" da reivindicação histórica de uma "vida mais elevada". De sua formação acadêmica, das aulas com vários representantes da escola neokantiana historicista, destacaram-se os argumentos filosóficos que, aliados a uma série de leituras tão distintas quanto Nietzsche ou Goethe, o levaram à constituição de um peculiar imbricamento entre filosofia da história e filosofia da vida que passou a marcar boa parte de seus escritos futuros. Da vida de juventude, observa-se a formulação de uma compreensão acerca da ideia de vida que permanecerá por muito tempo no pensamento benjaminiano. A seguir, pretendemos apresentar algumas dessas discussões juvenis no momento de formação escolar junto à proposta de reforma da vida.

\section{A reforma da vida (Lebensreform)}

Pode-se afirmar que o primeiro contato de Walter Benjamin com a filosofia e, por sua vez, com a questão "vida", se deu quando este tinha 15 anos de idade e ocorreu na pequena cidade de Haubinda, na região da Turíngia, distante cerca de 400 quilômetros de Berlim, sua cidade natal ${ }^{2}$. Benjamin se encontrava estudando em um internato agrícola de uma das Comunidades Escolares

\footnotetext{
${ }^{2}$ Essas informações e outras igualmente significativas sobre esse contexto podem ser encontradas com ligeiras modificações em diversos escritos autobiográficos e biográficos, cartas de Benjamin e, também, em trabalhos de pesquisa sobre a fase de juventude de Walter Benjamin, principalmente em (BENJAMIN, 1991; 1994), (BENJAMIN; SCHOLEN, 1993), (SCHOLEM, 1989) e (PULLIERO, 2013).
} 
Livres, fundada a partir das propostas do movimento alemão de reforma escolar (Schulreform) derivadas diretamente da proposta filosófica de "reforma da vida" (Lebensreform) ${ }^{3}$. Os ideais da "reforma da vida" provinham de um amplo e diversificado movimento, de origem romântica, que pregava, entre outras coisas, o "retorno à natureza", a vida saudável, o trabalho coletivo e a moradia em comunidades solidárias (Cf. BRAGE e CAÑELLAS, 2011, p.82). O jovem, ainda um garoto, Walter Benjamin foi matriculado em uma dessas comunidades escolares após ter passado por uma série de dificuldades em um dos clássicos e rigorosos colégios prussianos de Berlim. Essa comunidade escolar se coloca como antípoda reformista do tradicional colégio Kaiser-Friedrich Gymnasium, onde Benjamin estudará e para onde retornaria e receberia mais tarde, em 1912, seu Abitur, título de conclusão do ensino básico, que o credenciaria ao ingresso em uma universidade ${ }^{4}$. Algumas dessas dificuldades escolares desse período, como punições por atrasos, rigor hierárquico e opressão disciplinar são relatados em diversas passagens ao longo dos escritos de Benjamin, com destaque para a obra autobiográfica Infância em Berlim por volta de 1900 (1934).

Nos informa Palmier (2006, p.79) que, diferentemente das impressões que guardou da vida no rigoroso colégio prussiano, Benjamin reconhece que na comunidade escolar de Haubinda "foram plantadas as sementes de sua vida futura". Lá, ele encontrou certo tipo de estabelecimento de ensino que oferecia aos alunos a liberdade de organização de seu tempo e de seus estudos e que incentivava, acima de tudo, o desenvolvimento autônomo de suas personalidades. Em um pequeno ensaio intitulado "A comunidade escolar livre" (1911), Benjamin defende a proposta de uma escola como a de Haubinda, que valorize o significado da juventude como o momento decisivo de uma vida grandiosa:

Os jovens realmente são capazes de tais convicções sérias [de trabalhar para os mais altos ideais], de um compromisso tão sagrado? [...] "Quem olha a juventude... como apenas um período de preparação sem valor em si, quem olha para a escola apenas como um exercício preparatório anterior à luta pela existência, que é compreendido como o verdadeiro significado da vida - pode, tão somente, não ter a apreciação de qualquer aprofundamento e sacralização do ensinar e do aprender". [...] Os interesses da vida profissional, voltados para a família, ainda não estreitaram o horizonte pessoal do jovem. E consequentemente, mas carregado com peso ainda maior: o jovem ainda não sabe dos dias de monotonia, a uniformidade dos costumes convencionados, "o eterno Ontem que sempre foi e sempre retorna" que é o pior inimigo de tudo que é

\footnotetext{
3 O movimento da "reforma da vida", surgido em meados do século XIX, foi fortemente marcado pelas ideias e valores de vários teóricos do romantismo e, até as décadas de 1960 e 1970, na Alemanha e em outros países, inspirou diferentes tendências e movimentos em um amplo espectro político, religioso, social e cultural, ao exemplo de grupos de ecologistas, naturistas, anarquistas, orientalistas até grupos socialistas e mesmo nacionalistas. São exemplos da influência dos ideais da "reforma da vida" parte dos grupos de contracultura bippie dos conturbados anos 1960, nos EUA. A busca pela compreensão dos desdobramentos dos ideais da "reforma da vida", em diferentes aspectos da cultura das sociedades contemporâneas, tem se tornado objeto de estudo cada vez mais crescente. A título de exemplo, destacamos a pesquisa desenvolvida no programa de Pós-graduação em Educação na Universidade Federal de Santa Catarina, coordenado pelo professor Dr. Alexandre Fernades Vaz, e o seminário internacional "A reforma da vida", realizado em outubro de 2013, na Universidade Federal do Rio de Janeiro.

${ }^{4}$ Uma excelente alegoria crítica das tradicionais instituições de ensino alemãs, e por sua vez de toda vida da juventude da época, pode ser também encontrada na obra Jakob von Gunten (1909) do escritor Robert Walser (1878-1956). Benjamin dedicou um pequeno ensaio sobre esse escritor intitulado "Robert Walser" (1929).
} 
grandioso (BENJAMIN, 2011, p.41,). ${ }^{5}$

Haubinda buscava a reforma de uma vida estreitada pela perspectiva unicamente de instrução profissional para se alcançar a condição adequada de realização de uma vida grandiosa. Essa comunidade escolar livre desenvolveu uma pedagogia progressista que compreendia o equilíbrio entre atividades práticas e teóricas, na qual a distância hierárquica entre alunos e mestres fora abolida e um clima de idealismo filosófico imperava ${ }^{6}$. Para Marc Berdet (2014, p.28), esse idealismo compreendia uma espécie de "programa hegeliano" que imperava na proposta das comunidades escolares livres. Esse "programa" defendia que a educação visava arrebanhar das personalidades individuais seu "espírito subjetivo" (sentimentos, paixões, inclinações) para lhes submeter ao "espírito objetivo" da moral, das leis e do Estado, buscando, por sua vez, ascender cada vez mais ao "espírito absoluto" da arte, da religião e da filosofia. Para Benjamin (2011, p. 40), "todos os bens ideais, a linguagem e a ciência, o direito e a moral, a arte e a religião são expressões deste espírito objetivo”. Berdet destaca que Benjamin insiste ainda que é a vida que anima o espírito absoluto hegeliano. Esse "espírito absoluto designa no jovem Benjamin um sujeito vivo que pode se juntar às criações dos gênios da humanidade" (BERDET, 2014, p. 29). Foi com a ajuda do pedagogo Gustav Wyneken (1875-1964) que Benjamin tomou contato com o idealismo hegeliano e o adotou como programa juvenil de reforma escolar. Pouco tempo depois, por volta de 1918, Benjamin romperá com o idealismo hegeliano acusando a noção de espírito absoluto como um misticismo violento (Cf. BENJAMIN, 1979, p. 158). Berdet explica (2014, p. 33) que o contato com o neokantismo ajudara a compreender a impossibilidade de uma síntese tamanha como a do espírito absoluto hegeliano em relação aquilo que se apresenta múltiplo e heterogêneo como a vida.

Foi justamente o contato com o então jovem professor Wyneken que viria deixar as marcas mais profundas nesse momento de formação do pensamento de Benjamin. Os pesquisadores espanhóis Brage e Cañellas (2011, p. 81) defendem que as ideias filosóficas e educacionais do pedagogo podem ser agrupadas em torno dos seguintes pontos:

a) O idealismo, próprio do pensamento alemão, desde Hegel e Fichte, passando ainda pelas obras sobre educação de Schiller e Schelling, e culminando com Dilthey e a escola neokantiana de Marburgo, que se acercaram das questões pedagógicas e acompanharam as propostas reformistas;

b) A questão do "eros pedagógico", o amor, a estima que o professor deve ter para com seus alunos, de onde se extrairiam, entre outras coisas, o sentido da amizade, o clima de confiança, a liberdade, a independência e a autogestão, que devem impregnar a comunidade escolar, e que, por sua vez, devem ser o vértice das relações;

\footnotetext{
${ }^{5}$ Utilizamos diferentes traduções das obras de Benjamin, bem como o cotejo com os escritos originais em alemão (BENJAMIN, 1991) e mantivemos termos na língua originária quando da necessidade de ênfase ou destaque. ${ }^{6} \mathrm{O}$ estabelecimento de ensino inovador e reformista de Haubinda foi fundado por Hermann Lietz, em 1901, e passou, a partir de 1904, a ser dirigido pelos pedagogos Paul Geheeb (1870-1961) e Gustav Wyneken (1875-1964) e foi o resultado mais visível das propostas da reforma escolar alemã do final do século XIX e início do século XX (Cf. BRAGE e CAÑELLAS, 2011, p.82).
} 
c) O conceito de Jugendkultur, de cultura juvenil, com o qual Wyneken queria assentar a noção de formação patrocinando uma diferenciação específica do jovem em referência ao adulto. Educar teria que favorecer o desenvolvimento autônomo do jovem, e a escola, por sua vez, teria que oferecer soluções para todas as necessidades, ambições e interesses juvenis, com vistas ao respeito de uma cultura própria juvenil.

O sentido comunitário no qual deve enquadrar-se todo o processo educativo e que, como consequência, seria o fator para o sucesso da cultura juvenil, assim como a expressão dos valores que deve acompanhá-lo. A moral, o patriotismo, o cumprimento do dever, o trabalho, tudo nas instituições de ensino deve ter sentido comunitário. Fora da comunidade não existe educação possível. O pedagogo reformista, além de principal influência, foi grande amigo e interlocutor do jovem Benjamin no período entre os últimos anos do colégio e os primeiros anos de formação universitária. Em grande parte, foram as ideias de Wyneken que levaram Benjamin às atividades do movimento estudantil, nas quais atuou até o ano de início da Primeira Guerra Mundial, em 1914. Fortemente marcado pelas ideias românticas e pelo idealismo alemão, Wyneken defendia uma ampla reforma pedagógica, voltada para a mudança da vida por meio da promoção de autêntica cultura jovem ${ }^{7}$. Defendia um movimento cultural jovem (Jugendkulturbewegung) que estivesse comprometido com o sentido da liberdade na educação e que, como missão, pudesse desenvolver o espírito por meio da arte, do conhecimento científico aliado ao desenvolvimento da sensibilidade e, dessa maneira, tivesse que culminar necessariamente na formação de um verdadeiro e renovado Estado cultural.

\section{Reforma, juventude e formação}

Entre os anos 1911 e 1912, inspiradas em ideias reformistas, surgem, na Alemanha, as "Organizações estudantis livres" (Freistudentische Organisationen), grupos da juventude com ideais de transformar a realidade educacional cuja estrutura se baseava nas ideias de Wyneken. Esses grupos tinham tendências mais radicais em relação à postura ingênua e romântica dos grupos chamados "Aves migratórias" (Wandervögel) e se opunham às chamadas Burschenschaften, fraternidades estudantis fundadas a partir de 1815 no contexto das guerras napoleônicas e que, nas primeiras décadas do século XX, assumiram posturas mais conservadoras, mesmo reacionárias, nacionalistas e antissemitas. Boa parte dos escritos de Benjamin desse período reflete as tensões desse contexto de sua participação nos

\footnotetext{
${ }^{7}$ Podemos perceber certo tipo de filosofia da vida com origem no pensamento romântico que inspirou a noção de "reforma da vida" dessa época. Boa parte do romantismo destaca a relação entre vida e arte por meio da valorização dos impulsos (vontades ou sentimentos) como complementares ao esquematismo do conhecimento proposto por Kant. Para F. Schiller (1759-1805), a partir da representação estética da natureza, e da vida enquanto parte dessa natureza, surge uma "forma viva" (das gestalt Leben) de beleza. Essa "forma viva" se apresenta entre a relação entre impulsos sensíveis, no nível das impressões, e impulsos formais, conceituais, no nível do entendimento. Para Schiller, esse caráter pulsional presente na representação da vida servirá como a base para um projeto de reforma da vida por meio da educação estética do homem (Cf. F. SCHILLER, A educação estética do homem, 2002, p.77.)
} 
movimentos de juventude ${ }^{8}$ tendo, principalmente, as revistas oficiais desses grupos ${ }^{9}$ como espaço para a publicação de grande parte de seus trabalhos. Segundo Palmier (2006, p. 127-128), os escritos da juventude de Benjamin "encarnam uma vontade de ruptura radical com o mundo burguês" e trazem consigo “a aparição de exigências e de conceitos, como o de 'experiência' que marcarão todo seu pensamento".

O que encanta Benjamin em relação à $\mathrm{W}_{y}$ neken ${ }^{10}$ nessa época é sua oposição à condução da vida dos jovens ao nacionalismo da era guilhermina ${ }^{11}$ e aos valores reacionários das instituições de ensino e das antigas e conservadoras corporações estudantis criadas no início do século XIX. Para tal fim, o que também chama atenção de Benjamin como alternativa reformadora da vida e da juventude é a defesa do retorno e sua respectiva renovação crítica da tradição romântica de Humbolt e a luta pela autonomia da juventude no processo educacional (PALMIER, 2006, p. 82). Para os pesquisadores Caroline Mitrovich (2011, p. 75) e Marino Pulliero (2013, p. 390), o pensamento de Benjamin voltado para a questão educacional e influenciado por Wyneken busca resgatar o potencial crítico da chamada Bildung alemã. O termo Bildung, grosso modo, relaciona-se com a noção de formação e de educação. Especificamente, o termo consagrou certa proposta humanista e iluminista de educação na Alemanha a partir do século XVIII. No entanto, o termo carrega uma série de outros significados e desdobramentos de cunhos religioso, político, pedagógico e filosófico ${ }^{12}$. Em "A reforma escolar: um movimento cultural" (1912), artigo publicado por Benjamin com o pseudônimo de Eckhart no jornal do movimento de reforma escolar, encontramos a defesa da retomada da escola como aquela que pode promover a autonomia dos jovens para a formação cultural (Bildung). Citamos Benjamin:

A cultura do futuro é a única meta da escola e por isso terá de guardar silêncio ante o futuro presente em estado germinal na juventude que sai ao seu encontro. Inclusive deve deixar a juventude criar: deve bastar a si possibilitar e impulsionar a liberdade. [...] a mais urgente necessidade da pedagogia moderna não é outra que a criação de um espaço adequado para que a cultura se autodesenvolva (BENJAMIN, 1993, p. 51-52).

\footnotetext{
8 Após intensa participação nas atividades dos movimentos de juventude, em maio de 1914, Walter Benjamin assume a direção do "Estudantado Livre de Berlim" (Berliner Freie Studendtschaft), no qual permanecerá até o início da Primeira Guerra Mundial. É desse período de transição entre o ginásio e a universidade e de seu engajamento nos movimentos estudantis que temos o registro, por meio de cartas, da gênese do pensamento de Benjamin por meio de sua interlocução com amigos e companheiros, como Herbert Belmore, Carla Seligson, Franz Sachs, Ernst Schoen, Alfred e Jula Cohn e o poeta Fritz Heinle, que cometeu suicídio junto com sua noiva no contexto da eclosão da Primeira Guerra Mundial (PALMIER, 2006). ${ }^{9}$ A maior parte dos escritos de Benjamin, entre os anos 1911 e 1915, foi publicada utilizando pseudônimos, como Ardor ou Eckhart (para evitar represálias), em revistas ligadas ao movimento estudantil, como a Der Anfang, ligada à Wyneken, a Der Aktion, ligada a Kurt Hiller, ou a Der student, ligada ao estudantado livre da Universidade de Berlim.

${ }^{10}$ Os escritos de Gustav Wyneken chegaram a ter tiragens com mais de dez mil exemplares e foram largamente difundidos entre os estudantes secundaristas e universitários da época. Graças ao livro Cultura Juvenil (Jugendkultur), lançado em 1913, diversos círculos estudantis foram formados configurando-se o que se chamou de Fórum de Debates da Juventude (Sprechsaal der jugend). Gershom Scholem (1989, p.11-12) relata que conheceu Benjamin em 1914 participando de um desses fóruns. Relata também que nesses fóruns Benjamin defendia as ideias de uma reforma educacional radical, a autonomia de uma cultura jovem e que tinha como texto-manifesto básico justamente a obra Cultura juvenil, de Wyneken.

${ }^{11}$ A "Era Guilhermina” foi o período da história alemã que antecedeu a $1^{\text {a }}$ Guerra Mundial e foi marcado pelo crescente imperialismo e militarismo do país.

12 Para aprofundamento sobre o tema, sugerimos a leitura de Walter Benjamin: Le désir d'authenticité (2013), de Marino Pulliero (há um anexo sobre a gênese e desenvolvimento da noção de Bildung).
} 
Assim como Benjamin, cada vez mais adeptos do pensamento de Wyneken recebiam uma herança reformista de ideais românticos e idealistas da Bildung. Wyneken tornava-se, por meio de suas atividades pedagógicas $^{13}$, suas ações de ativismo reformista junto aos movimentos estudantis ${ }^{14}$ e, sobretudo, devido às suas obras ${ }^{15}$, o principal interlocutor no debate sobre a reforma do modo de formação (Bildung) educacional e cultural da juventude.

Em uma carta de junho de 1913 a Carla Seligson (1892-1956) ${ }^{16}$, sua amiga e sua confidente de movimento de juventude, Benjamin declara:

Meu pensamento parte sempre de meu primeiro mestre Wyneken, e a ele retorna. Mesmo sobre questões abstratas [os ideais da juventude na Universidade], já pressinto a resposta que ele daria (BENJAMIN, 1979, p. 54-55).

Uma determinada noção em relação ao tema vida presente nos escritos de Benjamin desse período tem sua origem nas ideias reformistas de Wyneken. O pensamento de Wyneken está ligado à tradição romântica e idealista alemã, e esta, por sua vez, enfatizava a vivacidade da sensibilidade e do estético como crítica ou correção dos exageros de um estático intelectualismo iluminista; suas propostas de reforma escolar derivam de um movimento, também romântico, que propunha a reforma da vida; sua proposta de formação de uma cultura juvenil tinha em vista o viver uma vida grandiosa, uma "vida da totalidade" como a opção de mudança para uma sociedade voltada para os aspectos criativos e plenos da vida (WYNEKEN, 1927, p. 17); por fim, defendia a realização da vida e do espírito em uma espécie de nova religião, que se insurgisse contra a derrocada de todas as relações sociais tradicionais provocadas pelo desenvolvimento do mundo capitalista mecanizado e sua racionalidade meramente instrumental. Para tanto, uma reforma completa na forma de viver das pessoas deveria ser estabelecida. E essa "reforma da vida", assumiria Benjamin, passaria necessariamente pela "reforma da juventude":

Assim se desperta cada vez mais a consciência dos valores absolutos próprios deste juvenil sentido de alegria e honradez. E já está assinalada a necessidade de que este sentimento juvenil se converta em um modo de pensar comum a todos, se converta em uma bússola da vida (BENJAMIN, 1993, p. 52).

\footnotetext{
13 Após a experiência de Haubinda, Wyneken fundou sua própria comunidade escolar livre na vila de Wickersdorf, na mesma região da Turingia, de onde somente viria a sair em 1921 (BRAGE e CAÑELLAS, 2011).

${ }^{14}$ Gustav Wyneken não ingressou oficialmente em nenhum grupo jovem, mas influenciou e mesmo participou de atividades de diferentes movimentos, tais como os românticos escotistas dos Wandervogel (aves migratórias) ou o grandioso evento jovem na vila de Hohem Meissner, considerado o "festival da juventude", no qual Benjamin participou, e que ocorreu em outubro de 1913 reunindo movimentos jovens de várias tendências. Além dessas participações, o ativismo de Wyneken encontrou espaço em várias palestras e seminários realizados em diversas instituições de ensino alemãs (Cf. PALMIER, 2006, p.135-137).

${ }^{15}$ Cabe destacar que alguns trabalhos de Wyneken, como de seus seguidores do movimento jovem, ao exemplo de Benjamin, foram publicados na revista Der Anfang (O Comeşo) que, nas palavras do próprio Wyneken (1927, p.14), tinham por objetivo "ouvir a juventude, dar-lhe a ocasião para discutir livremente, sem tutela, suas concepções, desejos e ideais, mas também para comentar suas necessidades e defender-se da ignorância e opressão”.

${ }^{16}$ Carla Seligson foi uma das amigas mais próximas de Benjamin no período. Casou-se com Herbert Belmore, outro amigo e importante interlocutor de Benjamin, e também era irmã de Rika Seligson, que se suicidou com Fritz Heine no início da primeira grande guerra (Cf. BENJAMIN, 1994).
} 
E os ponteiros dessa bússola certamente consistem nas palavras encontradas na obra Escola e Cultura Juvenil, publicada por Wyneken em 1917. Nessa obra lida a esmo por Benjamin, Wyneken destaca que o mundo moderno promoveu novas e vitoriosas descobertas no campo da técnica, mas que, entretanto, nossos juízos morais ainda toleram inúmeras dificuldades e contradições da vida social que poderiam, em grande parte, ser superadas tais quais as dificuldades encontradas no campo da técnica. Em outras palavras (WYNEKEN, 1927, p. 27), “o grande problema de toda nossa vida pública e social é a discrepância entre o desenvolvimento material e técnico e o ideal, jurídico e moral". A reforma da vida moderna, materialmente e tecnicamente desenvolvida, deve ser assumida como uma missão pela juventude no sentido (histórico) de constituição moral e espiritual de uma vida plena. Em uma carta ao seu amigo Herbert Belmore, de maio de 1913, Benjamin declara a influência de Wyneken como essa missão juvenil: "eu sinto que estou no coração da missão de Wyneken que é o de conduzir as pessoas à sua juventude".

Mas o que representaria esse "conduzir as pessoas à sua juventude"? Acreditamos que essa afirmação pode ser interpretada como referência vitalista no pensamento de Benjamin. No melhor espírito nietzschiano que imperava na época ${ }^{17}$, conduzir as pessoas à sua juventude representaria conduzi-las a uma nova "forma de vida", menos comprometida com os rigores exigidos pela sociedade moderna, "filisteia", industrial e capitalista que nega uma vontade "jovem" de vida.

Com Nietzsche se ampliou criticamente o conjunto de argumentos vitalista predominante no século XIX, auxiliando a nortear as filosofias da vida que surgiram no século XX e que estavam presentes no contexto da juventude de Benjamin. O pensamento vitalista de Nietzsche, como herança de Schopenhauer, defende a existência de uma vontade de poder (Wille zum Macht) que marca todas as expressões da vida como uma constante vontade de vida (Wille zum Leben). A título de exemplo, em Assim falou Zaratustra $(1883)^{18}$, obra muitas vezes mencionada por Benjamin, Nietzsche (1998, p.127) apresenta o que pode ser caracterizado como o mote da geração, segundo ele “onde há vida, há vontade de poder”. Informa-nos Marino Pulliero (2013, p.384-385) que nessa época de juventude de Benjamin havia uma espécie de culto à figura de Nietzsche, um "evangelho" do além do homem (Übermensch), ou ainda, um "estilo Zaratustra" (Zarathustrasti) entre muitos teóricos e acadêmicos. Para Schnädelbach (2009) e para Lebovic (2011), as maiores contribuições de Nietzsche para o debate em torno do tema vida no contexto de formação do pensamento de Benjamin situam-se na discussão sobre a relação dessa vontade de vida com a temporalidade ou mais precisamente com a história. A defesa da vida como vontade ajudou a estabelecer um critério para a avaliação, pela perspectiva da crítica cultural (que

\footnotetext{
${ }^{17}$ No âmbito acadêmico ressoava fortemente a recepção crítica da obra de F. Nietzsche intitulada "Sobre o futuro de nossos estabelecimentos de ensino" (1872) na qual encontramos, entre outros aspectos, a defesa de um processo educacional (Bildung) que não formasse indivíduos apenas para o Estado e para a vida profissional (Cf. PULLIERO, 2013, p.378-383). Escrito disponível na coletânea "Escritos sobre educação" (NIETZSCHE, 2012).

18 Obra esta que "participou" da formação acadêmica do jovem Benjamin, como pode atestar diversas referências em seus textos, como o caso do ensaio paradigmático da juventude de Benjamin (2012), intitulado "A vida dos estudantes" (1915), e também menções em cartas e conversas trocadas com amigos dessa época, ao exemplo das menções contidas no livro História de uma amizade de G. Scholem (1989).
} 
foi em grande parte assumida por Benjamin), dos processos históricos de autoalienação da vontade e mesmo de negação ou contrários à vida. Nietzsche (2009) aponta para uma teoria da decadence ocidental, na qual o niilismo seria a constatação de um processo histórico durante o qual os valores tradicionais que, por assim dizer, "sustentavam" uma determinada concepção de vida, tidos como valores supremos, ao exemplo de Deus, o bem ou a verdade, perdem o valor e perecem.

Para Schnädelbach (2009, p. 156), a vida, mesmo como vontade de poder, permitiu que Nietzsche sugerisse o estabelecimento de um critério para o estabelecimento de uma vida apropriada, ou mesmo de uma vida correta. Na perspectiva desse mesmo pesquisador (Idem, p. 157), a tarefa de Nietzsche, de crítica da negação da vontade por meio do pessimismo e da decorrente decadência dos valores do ocidente, pode ser identificada em seus primeiros escritos, na avaliação do trágico e do contraste entre os impulsos apolíneos (de natureza formativa, valorativa, racionalizante) e dionisíacos (de natureza expressiva, criativa, jovem e "viva") e no posterior diagnóstico do declínio do dionisíaco na cultura; bem como pode ser observada nas obras que tratam da genealogia dos valores, do desmascaramento de ideias tradicionais e da proposta crítica de "transvaloração de valores". Nisso situa-se a missão de Benjamin de "levar as pessoas às suas juventudes".

\section{Considerações finais}

No início, influenciados pelas ideias reformistas de Wyneken, pelos debates sobre juventude, cultura, educação e religiosidade, passando pelas múltiplas influências de Kierkegaard a Nietzsche, os escritos de Benjamin logo vão ganhando contornos próprios e conquistando independência de pensamento $^{19}$. Alguns fatos biográficos podem ser considerados decisivos para esse processo de conquista de autonomia intelectual de Benjamin, tais como os desentendimentos em relação à tentativa de Wyneken de tutela e direcionamento dos movimentos estudantis ${ }^{20}$, o que mais tarde levaria ao total rompimento de relações após a defesa por Wyneken da participação dos jovens na Primeira Guerra Mundial (1914-1918) por meio do manifesto "Juventude e Guerra" (1914)²1; seu fracasso na direção do estudantado livre de Berlim, no qual ficaria poucos meses, e sobre protestos dos demais estudantes, o

\footnotetext{
${ }^{19}$ Para o pesquisador francês Marc Berdet (2014), o pensamento de Benjamin é marcado pela constante tensão dialética entre opostos. No caso, a tensão entre Nietzsche e o pensamento kantiano, entre o idealismo e o romantismo e o materialismo e entre esse e o judaísmo.

${ }^{20}$ Benjamin defendia uma autonomia do espírito jovem em relação à formação de uma cultura genuinamente jovem, o que o levava a condenar qualquer uso da juventude por partidos políticos (daí sua opção por um movimento livre de estudantes), pelo Estado, pelas relações burguesas do mercado de trabalho, pelas instituições de ensino e, no melhor espírito kantiano, combatia qualquer tutela da juventude. Em um texto do final do ano de 1913, apresentado no Primeiro Congresso Pedagógico Estudantil, chega a defender que os jovens não devem ser “uns fanáticos partidários de Gustav Wyneken” e que não deveriam "averiguar a qual dos reformadores escolares de hoje temos que seguir, senão que estamos tentando desenvolver as coisas a partir de nós mesmos” (Cf. BENJAMIN apud BRAGE e CAÑELLAS, 2011, p.85).

${ }^{21}$ Em uma conhecida carta, de 9 de março de 1915, Benjamin (1994, p.75) emocionadamente rompe com Wyneken e o acusa de monstruosa traição aos ideais do movimento de juventude.
} 
que causaria seu desapontamento com o propósito de reforma estudantil, evidenciado com a crescente adesão dos jovens com as causas da guerra; e, por fim, os suicídios dos amigos de Benjamin, o poeta Fritz Heinle e sua noiva Rika Seligson, em razão de desespero e protesto contra o avanço da grande guerra. Tais acontecimentos o levam a se afastar em definitivo do movimento estudantil, rompendo, assim, com diversos colegas e amigos, e o levam a mudar-se para Munique para a conclusão de sua faculdade e, logo, com o avanço da guerra, o fazem mudar novamente para Berna, na Suíça, onde realizará seu doutoramento. Steiner (2010) e Brage e Cañellas (2011) argumentam que os escritos de juventude, do período de participação no ativismo estudantil, apresentam as sementes de uma característica crucial do pensamento de Walter Benjamin, a saber, as relações entre razão e existência, entre entendimento e sensibilidade, ou, por fim, a dialética entre a intelectualidade e a vida. Algo que é ainda caracterizado por Pulliero (2013) como desejo de autenticidade em relação à vida que Benjamin herdou das propostas filosóficas idealistas e românticas alemãs.

Comprovando em parte os argumentos anteriores, podemos identificar em uma carta de Benjamin (1979, p. 43), de abril de 1913, endereçada a Carla Seligson, a declaração de que suas leituras o levavam, questão após questão, para algo que tinha sempre como prognóstico, mas que ele ainda não havia articulado e que, naquele momento, colocava-se como ultimato: "Esteticismo ou moralidade?". Nessa carta, Benjamin (1979, p.44) declara:

Quando algumas páginas de Kant me fatigam, eu descanso em Kierkegaard. Saiba que sem dúvida, sobre o solo da ética cristã (ou judaica, se preferir) ele exige o mesmo rigor e o mesmo heroísmo que Nietzsche sobre outro terreno e, como ele, realiza uma análise psicológica destrutiva. Enter-Eller é um ultimato: esteticismo ou moralidade?

A possibilidade de escolha entre o estético ou o moral, dilema vivenciado por Benjamin nesse contexto de juventude, certamente é resultado do impacto da leitura da obra "existencial" Enter-Eller (1843) de Søren Kierkegaard (1813-1855). E justamente a partir da oscilação entre essas duas esferas, apresentadas por esse questionamento, um $A u t$-aut ("ou isso ou aquilo") de inspiração kierkegaardiana, que optamos por avaliar a ideia de vida nos escritos de juventude de Walter Benjamin.

Os textos desse período de gênese do pensamento benjaminiano, diante do quadro de uma eminente possibilidade de reforma de toda vida, são marcados pela influência de Wyneken, pelos debates no interior do movimento de juventude, pelas ressonâncias das atividades acadêmicas de formação universitária ou, ainda, pelo calor da proximidade de uma guerra de proporções mundiais. Textos cujas temáticas fazem a noção da vida oscilar entre questões indireta ou diretamente estéticas, tais como: reforma cultural, papel da arte, valor dos sentimentos, experiência do belo ou, ainda, em

\footnotetext{
22 A temática da escolha, da decisão ou da tomada de posição em relação à vida, é elemento central da obra Enter-Eller (1843) de Kierkegaard, na qual o emprego da expressão latina aut-aut ("ou isso ou aquilo") revela tanto o momento decisório pessoal como o momento fundamental, o momento "sagrado", diria Benjamin, do processo de criação dos valores pessoais e de realização existencial. Sabe-se por cartas e relatos que essa obra foi marcante na formação universitária de Walter Benjamin, entre os anos de 1912 e 1916.
} 
relação à vivência do Eros, e, de outra parte, oscilar em torno de questões relativas à moralidade, sejam sobre delimitações conceituais (moralidade ou legalidade, por exemplo) ou sobre o ensino da moral, sobre valores de comunidade e valores individuais, sobre religião e religiosidade, sobre relações com o Estado, sobre casamento ou, por fim, sobre a possibilidade de uma vida moralmente mais elevada.

Essas oscilações também se fazem sentir no pano de fundo teórico que deu origem a essas questões, a saber, ora temos um Benjamin leitor e continuador do pensamento romântico, seja por conta própria ou via ideias reformistas, e, no mesmo sentido, observamos a presença do idealismo alemão; ora temos um Benjamin dialogando com o historicismo e que está a par, e muitas vezes à frente, dos problemas das tradições kantiana e neokantiana (vide a maioria de seus professores) e um Benjamin, talvez o mesmo Benjamin, que lê os clássicos (como Kierkegaard) e que sempre sente a proximidade crítica de Nietzsche.

\section{Referências}

BENJAMIN, Walter. Correspondance (1910-1928). Volume I. Traduction par Guy Petitdemange. Paris: Aubier Montaigne, 1979.

Gesammelte Schriften. Hrsg. von Rolf Tiedemann und H. Schweppenhaüser. Frankfurt am Main: Suhrkamp Verlag, 1991. 14 v.

. La metafísica de la juventud. Introducción de Ana Lucas, tradución de Luis Martinez de Velasco. Barcelona: Paidós, 1993.

Perspectiva, 1993.

SCHOLEM, Gerschom. Correspondência. Tradução de Neusa Soliz. São Paulo:

. The correspondence of Walter Benjamin. Translated by Manfred R. Jacobson and Evelyn M. Jacobson. Chicago: University Chicago Press, 1994.

Reflexões sobre a criança, o brinquedo e a educação. Tradução, apresentação e notas Marcus Vinícius Mazzari, pósfácio de Flávio di Giorgi. São Paulo: Duas Cidades; Editora 34, 2002.

Early Writings (1910-1917). Translated by Howard Eiland and Others. Cambridge: Harvard University Press, 2011.

Rua de mão única; Infância berlinense: 1900. Tradução de João Barrento. Belo

Horizonte: Autêntica, 2013.

BERDET, Marc. Walter Benjamin: la passion dialectique. Paris: Armand Colin, 2014. 
BRAGE, Lluís.; CAÑELLAS, Antonio. Juventude y pedagogia (sobre la génesis del pensamiento de Walter Benjamin). Revista Teoría de la Educación, Salamanca, v. 1, n. 23, p. 71-106, 2011. Disponível em: <http://campus.usal.es/ revistas_trabajo/index.php /1130-3743/article/viewFile/8579/8811>. Acesso em: 10 mar. 2018.

KIERKEGAARD, Sören. Estética y ética en la formación de la personalidad. Buenos Aires: Editorial Nova, 1955.

LEBOVIC, N. Life. Mafte'akh: lexical review of political thought. Tel Aviv, Issue 2e, p. 37-64. 2011. Disponível em: <http://mafteakh.tau.ac.il/en/issue-2e-winter-2011/life/>. Acesso em: 10 ago. 2012.

MITROVITCH, Carolina. Experiência e formação em Walter Benjamin. São Paulo: Editora Unesp, 2011.

NIETZSCHE, Friedrich. Assim falou Zaratustra. Tradução de Mario da Silva. Rio de Janeiro: Bertrand Brasil, 1998.

das Letras, 2009.

Genealogia da moral. Tradução, notas e posfácio de Paulo César de Souza. São Paulo: Cia

Escritos sobre educação. Tradução, apresentação e notas de Noéli Correia de Melo Sobrinho. Rio de Janeiro: Editora PUC-Rio; São Paulo: Loyola, 2012.

PALMIER, Jean Michel. Walter Benjamin: um itinéraire théorique. Édition établie, annoté et preséntée par Florent Perrier. Paris: Les Belles Lettres, 2006.

PULLIERO, Marino. Walter Benjamin: le désir d'authenticité. L'héritage de la Bildung allemande. Paris: Hermann, 2013.

SCHOLEM, Gerschom. Walter Benjamin: a história de uma amizade. São Paulo: Perspectiva, 1989.

SCHNÄDELBACH, Herbert. Philosophy in Germany (1831-1933). Translated by Eric Mathews. New York: Cambridge University Press, 2009.

SCHILLER, Friedrich. A educação estética do homem: numa série de cartas. Tradução de Roberto Schwarz e Márcio Suzuki. São Paulo: Iluminuras, 2002.

STEINER, Uwe. Walter Benjamin: an introduction to his work and thought. Translated by Michael Winkler. Chicago: University of Chicago Press, 2010.

WYNEKEN, Gustav. Escuela y cultura juvenil. Tomo II. Traducción de Lorenzo Luzuriaga. Madrid: La lectura, 1927. 
Aprovado em: 05 de junho de 2018. 